\title{
Impact of Student Engagement on Academic Performance and Quality of Relationships of Traditional and Nontraditional Students
}

\author{
Andrew Courtner ${ }^{1, *}$ \\ ${ }^{1}$ School of Education, Union University, 1050 Union University Drive, Jackson, Tennessee \\ 38305, United States \\ *Correspondence: E-mail: andrew.courtner@lmunet.edu
}

Received: March 18, 2014 Accepted: March 28, 2014 Published: May 12, 2014

doi:10.5296/ije.v6i2.5316 URL: http://dx.doi.org/10.5296/ije.v6i2.5316

\begin{abstract}
The purpose of this study was to determine the impact of the level of student engagement on academic performance and the quality of relationships with students, faculty, and administrative personnel of traditional and nontraditional students. This study sought to determine if there was a significant difference in academic performance of traditional and nontraditional college students based on the level of student engagement. The researcher examined data from both traditional and nontraditional students to consider the impact the level of student engagement had upon the quality of relationships with other students, faculty, and administrative personnel. Furthermore, the study sought to determine if there was a significant difference in the quality of relationships with other students, faculty, and administrative personnel between traditional and nontraditional college students. There was a significant difference between traditional and nontraditional students based on academic performance and level of student engagement. Traditional students had higher levels of student engagement; however, nontraditional students had higher levels of academic performance. Level of student engagement had a significant impact on the quality of relationships with other students, faculty, and administrative personnel for both traditional and nontraditional students. Specifically, level of student engagement had the greatest impact upon quality of relationships with faculty for both traditional and nontraditional students. Furthermore, there was a significant difference in the quality of relationships with other students, faculty, and administrative personnel. Nontraditional students had the highest quality of relationships with faculty and administrative personnel, and traditional students had the highest quality of relationships with other students.
\end{abstract}

Keywords: student engagement, traditional student, nontraditional student, academic performance, quality of relationships 


\section{Introduction}

The study of student engagement of college students during their educational and academic career has been a strong topic trending higher education. Extensive studies and research have been conducted on student engagement and the impact it may have upon the educational experience of the student (Astin, 1999; Kuh, 2005; Kuh, Kinzie, Buckley, Bridges, \& Hayek, 2007). The term and theory of student engagement is first introduced as the theory of student involvement by Alexander Astin (1984). When first introduced, Astin provides the reasoning for five main purposes and key components of the student engagement/involvement phenomena. Astin (1984) defines student engagement as "the amount of physical and psychological energy that the student devotes to the academic experience" (p. 518). This definition is used in the current study to define the theory of student engagement.

Within recent years, researchers have analyzed the impact student engagement has upon the educational and academic experience of college students, specifically academic performance. There are numerous studies that analyze the impact of student engagement upon academic performance and quality of relationships for traditional college students. However, there is very limited research that looks at the student engagement process and its impact on academic achievement for nontraditional students. Previous research also has looked at the relationships between students and faculty; however, there is limited research on the quality of relationships with other students, the quality of relationships with faculty, and the quality of relationships with administrative personnel. This study was designed to fill in these missing portions of research and add to the body of knowledge in this area.

\section{Literature Review}

The age of today's undergraduate population is becoming extremely more and more diverse. Adults are attending for the first time or returning to college in record numbers as the undergraduate landscape is expanding beyond the traditional 18- to 22-year old students (Bauman et al., 2004; Choy, 2002; Graham \& Gisi, 2000; Hernandez et al., 1999; Johnson \& Nussbaum, 2012; Keith, 2007; Kinsella, 1998; Lundberg, 2003a). This change has caused institutions, academic leaders, and scholars to examine the perception of traditional and nontraditional students and the operations and offerings of higher education institutions. Nontraditional students and traditional students have many differences and similarities in the levels of student engagement throughout their academic and educational experiences. There can also be specific benefits and effects depending on the level of student engagement. Therefore, within this review, the specific factors of the student engagement process of traditional and nontraditional students are analyzed and its impact upon academic performance and quality of relationships with other students, faculty, and administrative personnel.

\subsection{Defining Nontraditional Students}

The National Center for Education Statistics (NCES) defines a nontraditional student as having any of the following characteristics: 24 years of age or older; does not enter 
postsecondary education immediately after high school graduation; attends a college or university as part-time (or full-time) for at least part of the academic year; works 35 hours or more per week while enrolled; is considered financially independent by financial aid eligibility standards; has dependents other than spouse; is a single parent; or is recipient of General Educational Development (GED), other high school completion certificate, or did not complete high school (Choy, 2002; Macari, Maples, \& D’Andrea, 2005). Since age is the common variable throughout each definition, nontraditional students were defined as 24 years of age or older for the purposes of this study. This age range is used from the National Center for Education Statistics (Choy, 2002).

\subsection{Defining Traditional Students}

The definition of traditional students is not as varied or complex as the definition of nontraditional students. Traditional students are considered to be between the ages of 18 to 22 years old, live within college residences, and attend class full-time (Bean \& Metzner, 1985; Kim et al., 2010). The age of 23 was excluded from this study to allow for a distinct difference between 22 years of age and 24 years of age. This has been supported by previous research (Bean \& Metzner, 1985; Chao \& Good, 2004; Choy, 2002).

\subsection{Theoretical Framework of Student Engagement}

The use of the term student engagement did not emerge until the late 1990s/early 2000s. However, the ideas and premises of student engagement have existed in literature and in research for over 80 years (Astin, 1999; Kuh, 2005, 2009). Educational psychologist Ralph Tyler's (1969) work of "time on task" has been identified as a starting point of student engagement. Tyler first began his research at Ohio State University and continued it later at the University of Chicago. In his research, Tyler studied how much time students spent on their work and if there were any effects on learning. The research, indeed, showed there was a positive effect of time on task on student learning. Tyler's notion of time on task remains a component of today's definition of student engagement (Merwin, 1984; Tyler, 1969).

C. Robert Pace (1984) continued the research through his focus on quality of effort in the 1970s. Through his research, Pace found the need to be able to assess and evaluate higher education and the need to be able to measure the quality of experiences, not just the quantitative outcomes of increased knowledge and learning. Time spent was the quantitative measure, and effort was the qualitative measure of student experience. Pace stated the greatest measure of education is through effort. Therefore, in order to be able to measure effort, Pace created the College Student Experiences Questionnaire (CSEQ) in 1979. The CSEQ measures student development and learning by focusing on campus activities that are most common at higher education institutions. The questions only focus on activities and behaviors that contribute to learning, not on behaviors that take away from the educational environment. The CSEQ has a 4-point scale designed for the 14 content areas that are organized in a one-dimensional hierarchy. Therefore, the higher-order processes on the scale include the lower processes. Including the quality of student efforts, the questionnaire attains pertinent information such as demographics, educational goals, financial support, and overall approval of the college experience (Pace, 1984). 
In 1984, Alexander Astin studied the impact of college attendance on students. Within his research, he focused on the idea of student involvement (Axelson \& Flick, 2011). Astin (1984) defined the term student involvement as "the amount of physical and psychological energy that the student devotes to the academic experience” (p. 518). A highly involved student generally devoted a large amount of time and energy towards studying, was active in student organizations, spent a large amount of time on campus, and frequently engaged and interacted with faculty members and other students. A highly uninvolved student displayed the opposite characteristics of a highly involved student. However, there were other forms of involvement than the simple examples given (Astin, 1984; Axelson \& Flick, 2011). Involvement encompassed both the behavioral components of a student as well as the internal components. However, the behavioral components were viewed as more critical because internal components (e.g., motivation, stress, etc.) can influence how an individual behaves, which can define and identify their involvement (Astin, 1984). The theory of student involvement had five basic purposes:

1. Involvement referred to the investment made by the students of physical and psychological energy in various purposes. The purposes can be very broad (i.e., the entire educational experience) or highly specific (i.e., studying for a history examination).

2. Student engagement occurred along a continuum, no matter what the purpose is. "Different students manifest different degrees of involvement in a given [purpose], and the same student manifests different degrees of involvement in different [purposes] at different times” (Astin, 1984, p. 519).

3. Student involvement contained features that are both quantitative and qualitative. For example, the amount of time spent studying can be measured to infer the extent of student involvement, which is quantitative. The extent of student involvement can also measure qualitatively (i.e., whether a student comprehends a reading assignment or simply day dreams).

4. The quality and quantity of student involvement within any educational program was positively correlated to the amount of development and learning of the student.

5. The effectiveness of any program, policy, or practice of an institution was directly related to the ability to increase student involvement and engagement (Astin, 1984).

The theory of student involvement and its five basic principles were developed out of Astin's (1977) research in his book titled Four Critical Years: Effects of college on Attitudes, Beliefs, and Knowledge. Among the factors discussed, he placed large emphasis upon academic involvement and student-faculty interaction. The work focused mainly on 4-year institutions but has implications for all higher education institutions. Astin (1977) determined the strongest predictor of academic involvement was the inverse relationship with the doctrine of hedonism, which is the thought that happiness and pleasure are the sole good in life. Students who scored low on hedonism were more skillful at self-discipline and ignoring the desire for gratification, which led to increased persistence and success. He also determined the strongest 
predictor of student-faculty interaction was student interpersonal self-esteem. The degree to which students interacted with faculty was positively correlated to student self-esteem. Students living in campus housing also had a higher level of student-faculty interaction. Other student involvement variables had a positive association on grade point average. The variables included the number of hours spent on homework and studying, number of hours spent interacting with faculty outside of the classroom, and giving class presentations (Astin, 1977).

\section{Research Hypotheses}

To be discussed later, the data for this study were obtained from the 2010 National Survey Student Engagement. This data was used to investigate the following hypotheses:

1. There is a significant difference in academic performance of traditional and nontraditional college students based on the level of student engagement.

2. A traditional college student's level of student engagement has a significant impact on the quality of relationships that they have with other students, faculty, and administrative personnel.

3. A nontraditional college student's level of student engagement has a significant impact on the quality of relationships that they have with other students, faculty, and administrative personnel.

4. There is a significant difference in the quality of relationships that traditional college students have with other students, faculty, and administrative personnel compared to that of nontraditional college students.

\section{Research Methods}

\subsection{Variables}

The variables that were used were the level of student engagement, academic performance, quality of relationships with other students, quality of relationships with faculty, and quality of relationships with administrative personnel, as well as whether the subject was considered a traditional student or a nontraditional student. For the purposes of this study, the level of student engagement was identified by using the five benchmarks of effective educational practice that have been established by the NSSE survey. The five benchmarks are: (1) Level of Academic Challenge; (2) Active and Collaborative Learning; (3) Student-Faculty Interaction; (4) Supportive Campus Environment; and (5) Enriching Education Experiences. These five benchmarks are based on 42 key questions that capture many vital aspects and components of the student engagement process. . Each benchmark was represented by a score of 0 to 100. Researchers at NSSE used the responses to the specific questions for each benchmark to calculate the score (Kuh, 2003, 2009). 
Quality of Relationships was also another aspect of this study that is from the NSSE survey. This was based on the score of each student's responses to NSSE Question 8, Responses a, b, and c. NSSE Question 8 states, "Mark the box that best represents the quality of your relationships with people at your institution.” Question 8 responses are rated using a 7-point Likert scale of Unfriendly, Unsupportive, Sense of alienation $=1$ to Friendly, Supportive, Sense of belonging $=7$.

The self-reported grade on The College Student Report, the survey used by NSSE, was used to determine the student's academic performance. Question 25 of The Report asks, "What have most of your grades been up to now at this institution?” The grade options are: A, A-, $\mathrm{B}+$, B, B-, C+, C, C- or lower. For coding of analyzing data, the following codes were used: $A=8 ; A^{-}=7 ; B+=6 ; B=5 ; B-=4 ; C+=3 ; C=2$; and $C$ - or lower $=1$. These codes are used by NSSE and were coded in this manner in the data set obtained from NSSE.

In order to determine whether the participant was traditional or nontraditional, their age needed to be considered. As discussed earlier, traditional students were defined as 18 to 22 years of age, and nontraditional students were considered 24 years of age or older. Question 15 of the survey asks participants to write in their birth year. By having this question, the age of the participant was determined, which categorized whether they were a traditional or nontraditional student.

\subsection{Sample Selection}

For this study, the existing, secondary data was obtained from the 2010 National Survey of Student Engagement. The National Survey of Student Engagement used The College Student Report as their survey instrument to collect data. In 2010, 572 institutions within the United States participated in the NSSE survey. Since its development in 2000, over 1,500 institutions have participated (NSSE, 2010). The Report is administered to all $1^{\text {st }}$-year and senior year baccalaureate-seeking students, not just full-time students in the traditional 18- to 22-year old age range. Adult learners, full-time and part-time, commuters and residents, and distance education students are all included if seeking a baccalaureate and defined by credit hours. There were 393,630 total respondents for the 2010 survey. A sample size of 5\% of the population was used; thus, 18,250 traditional and nontraditional students were represented in the sample. The random sampling design ensured the specific characteristics of the entire population were represented in the sample (e.g., percentage of males/females, specific ethnicity and racial percentages, percentages of traditional and nontraditional students, etc.).

\subsection{Survey Instrument}

In the fall of 1998, the Pew Charitable Trusts met with higher education leaders and researchers to develop a better plan to assess and rank the quality of postsecondary institutions. It was determined that an undergraduate survey, if created and available, would provide a great opportunity for colleges and universities to improve quality and also enlighten the public as to what is important when evaluating institutions. After this initial meeting, scholars on college student development from across the nation convened and were given the challenge to develop a short survey instrument that would focus on the extent to which 
students engage in good educational habits and activities. By late 1998, a survey instrument had been developed and was ready for field-testing and two pilot cycles before it would go national in 2000. The national initiative was labeled as the National Survey of Student Engagement. In the first year of the national initiative, over 75,000 students from 276 different institutions participated within the survey (Kuh, 2001). After the first year of surveys in 2000, the five national benchmarks were developed: Level of Academic Challenge, Active and Collaborative Learning, Student-Faculty Interaction, Supportive Campus Environment, and Enriching Educational Experiences (Kuh, 2004).

The intended purpose of NSSE-restoring the ratings of college quality-has evolved into many other advantages. With so many institutions and students participating within the survey, it provided a comprehensive gathering tool to restart and reframe conservations about collegiate quality. One of the first advantages of NSSE data was for institutions in improving undergraduate education. The results that were gathered from The Report were also very valuable to external stakeholders such as accrediting bodies and government agencies. Finally, the data and information that was provided to the public can change the perception about media outlets' ratings of colleges (Kuh, 2003).

To be considered valid, self-reports must meet five conditions: when respondents know the information requested; if the questions are phrased clear and understandable; if respondents think the questions merit a serious and thoughtful response; the questions refer to activities that are recent; and answering the questions will not threaten, embarrass, or violate the privacy of respondents or encourage them to respond in socially desirable ways (Koljatic \& Kuh, 2001). Researchers intentionally designed The Report to meet these conditions (Kuh, 2004).

The survey instrument that is used to gather the data for NSSE is The College Student Report (hereafter referred to as The Report). The Report consists of 70 items that attempt to assess the extent to which students devote their time and energy towards educationally purposeful activities. The instrument deals with behaviors and actions that have been liked empirically to favorable outcomes in college. The Report was originally designed to provide process indicators or measures that could help institutions identify areas of improvement within student performance and institutional practices that would enhance the overall student experience. However, the results from The Report have been used by some institutions as a substitute for student learning (Carini et al., 2006). The Report is offered and available to $1^{\text {st }}$ and senior-year students at all participating institutions through the traditional paper and pencil and also a Web-based version (Kuh, 2001).

\subsection{Statistical Design}

This descriptive cross-sectional survey design study used the $19^{\text {th }}$ version of the Statistical Package for Social Sciences (SPSS) to analyze the data. After the scores from the National Survey of Student Engagement and codes of independent variables were entered into the statistical software program, the researcher ran several different statistical designs and methods in order to test the research hypotheses. 
For Research Hypothesis 1, two-way chi-square and Two-Group MANOVA were used to help determine if there is a significant difference in the academic performance (dependent variable) of traditional and nontraditional college students based on their level of student engagement (independent variable).

For Research Hypothesis 2, the nonparametric test Kendall's tau-b was used to help determine if the level of student engagement (independent variable) of traditional students had a significant impact on the quality of relationships with other students, quality of relationships with faculty, and quality of relationships with other students (dependent variables). Three separate Kendall's tau-b analyses were conducted for each relationship being studied.

For Research Hypothesis 3, the nonparametric test Kendall's tau-b was used to help determine if the level of student engagement (independent variable) of nontraditional students had a significant impact on the quality of relationships with other students, quality of relationships with faculty, and quality of relationships with other students (dependent variables). Three separate Kendall's tau-b analyses were conducted for each relationship being studied.

For Research Hypothesis 4, two-group MANOVA and the nonparametric test Mann-Whitney were used to help determine if there is a significant difference in the quality of relationships with other students, faculty, and administrative personnel (dependent variable) of traditional college students compared to that of nontraditional college students (independent variable). Two-group MANOVA was used because continuity and continuum of data was assumed since the Likert scale used to measure quality of relationships was 1 through 7 , instead of smaller ranges. However, to test the assumption of continuity and continuum, three separate Mann-Whitney tests were conducted to determine if there was a significant difference in the quality of relationships between traditional and nontraditional students.

\section{Findings}

\subsection{Participant Demographics}

The study was conducted with existing, secondary data obtained from the 2010 National Survey of Student Engagement from 572 institutions in the United States. A sample of 5\% was requested from the population of the 2010 NSSE database. Therefore, a sample size of 18,250 students was obtained. The sample was selected from the national group using random sampling, and the proportions of the sample were representative of the total population that participated in the survey. The sample consisted of the following ethnicities: 150 or $0.8 \%$ American Indian or other Native American; 1,084 or 5.8\% Asian, Asian American, or Pacific Islander; 1,629 or 8.9\% Black or African American; 12,200 or 66.8\% White (non-Hispanic); and 601 or 3.3\% Mexican or Mexican American. Two hundred five or 1.1\% Puerto Rican; 588 or 3.2\% Other Hispanic or Latino; 472 or 2.6\% Multiracial; 253 or $1.4 \%$ Other; 1,007 or $5.5 \%$ responded "I prefer not to respond"; 61 or $0.3 \%$ did not respond to the question of ethnicity. Male students totaled 6,545 or $35.9 \%$, and female students totaled 
11,666 or $63.9 \%$, with 39 or $0.2 \%$ not responding to the question of gender. Additionally, 8,204 or $45 \%$ were $1^{\text {st }}$-year students, and 10,046 or $55 \%$ were senior students. Finally, the sample consisted of 14,159 or $77.5 \%$ of traditional students (18-22 years of age), and 4,091 or $22.5 \%$ nontraditional students (24 years of age or older). Table 1 identifies the demographic details of the participants based on gender, race or ethnicity, classification, and student group.

\subsection{Research Hypothesis 1}

There is a significant difference in academic performance of traditional and nontraditional students based on the level of student engagement. For this research hypothesis, there were two statistical tests that were run to test this hypothesis. Alpha level of 0.05 was used for both of the statistical tests. In order to determine if there was a significant relationship between academic performance and student type of traditional and nontraditional students, a chi-square test of independence or a two-way chi-square was utilized. The dependent variable for this statistical test was academic performance (defined by grades as discussed in previous chapter), and the independent variable was student type (traditional or nontraditional). For this test, the minimum expected count was 52.52; thus, this assumption was not violated. In Chi-Square Tests box, the Pearson Chi-Square coefficient was 1,252.466, and the degrees of freedom was reported at $7(d f=7)$. The significance for this test was reported at $.000(p$ $<$.05). Therefore, there was a significant association between academic performance and student type. Academic performance was not independent of student type; it was dependent upon the student type. In the Crosstabulation Table, the observed count and its percentage for student type (traditional and nontraditional) were analyzed to determine the association. Of traditional students, $53.7 \%$ reported an A or A-; 42.7\% reported a grade of B+, B, or B-; and $3.4 \%$ reported a grade of $\mathrm{C}+\mathrm{C}$, or $\mathrm{C}$ - or lower. For nontraditional students, $61.2 \%$ reported a grade of $\mathrm{A}$ or $\mathrm{A}-;$; 35.7\% reported grades of $\mathrm{B}+$, B, or $\mathrm{B}-$; and $3.1 \%$ reported grades of $\mathrm{C}+, \mathrm{C}$, or C- or lower. Table 2 reports the observed count and percentages of each student type for each grade.

In order to understand if there is a significant difference between traditional and nontraditional students based on their level of student engagement, a multivariate analysis of variance or Two-group MANOVA was utilized. The dependent variable of student engagement was defined by the five benchmarks of effective educational experience (Level of Academic Challenge, Active and Collaborative Learning, Student-Faculty Interaction, Supportive Campus Environment, and Enriching Educational Experiences), and the student type (traditional or nontraditional) was the independent variable. Box's Test of Equality of Covariance Matrices was violated at a significance of .000; therefore, since Box's Test of Equality of Covariance Matrices was violated, Pillai's Trace was used. The multivariate tests reported significance at .000 for each main effect and with interaction under Pillai's Trace. A significance of .000 was reported for all independent variables (traditional or nontraditional) on the collection of the dependent variables (level of academic challenge, active and collaborative learning, student-faculty interaction, supportive campus environment, and enriching educational experiences). 
Levene's Test of Equality of Error Variances was accessed to determine if the variance of the levels or groups of the independent variable were the same. Significance was reported for level of academic challenge (.000), active and collaborative learning (.000), student-faculty interaction (.002), and supportive campus environment (.000), which violated Levene's. Enriching Educational Experiences (.064) did not violate Levene's. As a result, the significance category for each dependent variable was reviewed. In the tests of between-subject effects, significance was reported for student type (traditional or nontraditional) on the collection of dependent variables for four of the dependent variables: level of academic challenge at .000 , student-faculty interaction at .000 , supportive campus environment at .000 , and enriching educational experiences at .000. Active and collaborative learning did not cause a difference between the group since it had a significance level of .204.

Furthermore, in descriptive statistics, the means were analyzed further to see where the difference lay between traditional and nontraditional students based on level of academic challenge, student-faculty interaction, supportive campus environment, and enriching educational experiences. Based on the means, nontraditional students had higher levels of level of academic challenge $(M=57.446)$ compared to traditional students $(M=56.474)$. Regarding student-faculty interaction, traditional students had higher levels of interaction $(M$ $=40.014)$ compared to nontraditional students $(M=38.021)$. Traditional students also reported higher levels of support campus environment $(M=62.134)$ compared to nontraditional students $(M=59.674)$. Traditional students also had higher levels of enriching educational experiences $(M=36.461)$ compared to nontraditional students $(M=32.763)$. When looking at the total mean for both groups, the supportive campus environment benchmark had the highest reported mean at 61.583 .

\subsection{Research Hypothesis 2}

A traditional college student's level of student engagement has a significant impact on the quality of relationships that they have with other students, faculty, and administrative personnel. To be able to test this research hypothesis, the nonparametric test of Kendall's tau-b was utilized. Three different Kendall's tau-b tests were run to determine the impact a traditional college student's level of student engagement had upon quality of relationships with other students, quality of relationships with faculty, and quality of relationships with administrative personnel. Alpha level of 0.05 was used for each statistical test. Within the first statistical test, the independent variable was the level of student engagement, and the dependent variable was the quality of relationships with other students. In Symmetric Measures, significance was reported at .000. Therefore, since significance was reported, the Kendall's tau-b rank coefficient was analyzed. The Kendall's tau-b rank coefficient was reported at .327. The coefficient of .327 signified a weak correlation between level of student engagement and quality of relationships with other students. In the second Kendall's tau-b test, the independent variable was the level of student engagement, and the dependent variable was the quality of relationships with faculty. In Symmetric Measures, significance was reported at .000 . Therefore, since significance was reported, the Kendall's tau-b rank coefficient was analyzed. The Kendall's tau-b rank coefficient was reported at .398. The coefficient of .398 signified a weak correlation between level of student engagement and 
quality of relationships with faculty.

In the third Kendall's tau-b test, the independent variable was the level of student engagement, and the dependent variable was the quality of relationships with administrative personnel. In Symmetric Measures, significance was reported at .000. Therefore, since significance was reported, the Kendall's tau-b rank coefficient was analyzed. The Kendall's tau-b rank coefficient was reported at .284 . The coefficient of .284 signified a weak correlation between level of student engagement and quality of relationships administrative personnel. The positive correlation between the dependent and independent variable identified that the ranks of both variables were increasing. Thus, if the level of student engagement increases, the quality of relationships will increase as well. By examining each of the Kendall's tau-b rank coefficients, it could be determined the correlation between level of student engagement of traditional college students and quality of relationships with faculty was the greatest, with a reported coefficient of .398. Level of student engagement of traditional college students had the second largest impact on quality of relationships with other students with a reported coefficient of .327, and quality of relationships with administrative personnel was third with a reported coefficient of .284. Though the strongest relationships were represented by coefficients closest to 1.0, it is important to note that the large sample size was a factor in having smaller Kendall's tau-b rank coefficients. If the sample were smaller, the coefficients would be larger. Table 3 reports the Kendall tau-b coefficients and significance levels for each statistical test.

\subsection{Research Hypothesis 3}

A nontraditional college student's level of student engagement has a significant impact on the quality of relationships that they have with other students, faculty, and administrative personnel. To be able to test this research hypothesis, the nonparametric test of Kendall's tau-b was utilized. Three different Kendall's tau-b tests were run to determine the impact a nontraditional college student's level of student engagement had upon quality of relationships with other students, quality of relationships with faculty, and quality of relationships with administrative personnel. Alpha level of 0.05 was used for each statistical test. Within the first statistical test, the independent variable was the level of student engagement, and the dependent variable was the quality of relationships with other students. In Symmetric Measures, significance was reported at .000. Therefore, since significance was reported, the Kendall's tau-b rank coefficient was analyzed. The Kendall's tau-b rank coefficient was reported at .360. The coefficient of .360 signified a weak correlation between level of student engagement and quality of relationships with other students. In the second Kendall's tau-b test, the independent variable was the level of student engagement, and the dependent variable was the quality of relationships with faculty. In Symmetric Measures, significance was reported at .000 . Therefore, since significance was reported, the Kendall's tau-b rank coefficient was analyzed. The Kendall's tau-b rank coefficient was reported at .395. The coefficient of .395 signified a weak correlation between level of student engagement and quality of relationships with faculty. In the third Kendall's tau-b test, the independent variable was the level of student engagement, and the dependent variable was the quality of relationships with administrative personnel. In Symmetric Measures, significance was 
reported at .000 . Therefore, since significance was reported, the Kendall's tau-b rank coefficient was analyzed. The Kendall's tau-b rank coefficient was reported at .298. The coefficient of .298 signifies a weak correlation between level of student engagement and quality of relationships with administrative personnel. The positive correlation between the dependent and independent variable identified that the ranks of both variables were increasing. Thus, if the level of student engagement increases, the quality of relationships will increase as well. By examining each of the Kendall's tau-b rank coefficients, it could be determined the correlation between level of student engagement of nontraditional college students and quality of relationship with faculty was the greatest with a reported coefficient of .395. Level of student engagement of nontraditional students had the second largest impact on quality of relationships with other students, with a reported coefficient of .360, and quality of relationships with administrative personnel was third, with a reported coefficient of .298. Though strongest relationships were represented by coefficients closest to 1.0, it is important to note that the large sample size was a factor in having smaller Kendall's tau-b rank coefficients. If the sample were smaller, the coefficients would be larger. Table 4 reports the Kendall tau-b coefficients and significance levels for each statistical test.

\subsection{Research Hypothesis 4}

There is a significant difference in the quality of relationships that traditional students have with other students, faculty, and administrative personnel compared to that of nontraditional college students. To measure the quality of relationship, a Likert scale of 1 to 7 was used for the responses of the participants. Since the scale is more than 1 to 3 or 1 to 5 , the researcher was able to assume the continuity and continuum of data. Therefore, to be able to test the research hypothesis, the multivariate analysis of variance or Two-group MANOVA was utilized. The dependent variables were the quality of relationships with other students, quality of relationships with faculty, and quality of relationships with administrative personnel. Alpha level of 0.05 was used for each statistical test. Box's Test of Equality of Covariance Matrices was violated at a significance of .000; therefore, since Box's Test of Equality of Covariance Matrices was violated, Pillai's Trace was used. The multivariate tests reported significance at .000 for each main effect and with interaction under Pillai's Trace. A significance of .000 was reported for all independent variables (traditional or nontraditional) on the collection of the dependent variables (quality of relationships with other students, quality of relationships with faculty, and quality of relationships with administrative personnel).

Levene's Test of Equality of Error Variances was consulted to determine if the variance of each dependent variable was the same as the variance of all other dependent variables included in the analysis. Significance was reported for all dependent variables at .000 , thus violating Levene's. As a result, the significance category for each dependent variable was reviewed. In the tests of between-subject effects, significance was reported for student type on the collect of dependent variables: quality of relationships with other students at .000 , quality of relationships with faculty at .000 , and quality of relationships with administrative personnel at .000 . 
Furthermore, in descriptive statistics, the means were analyzed further to see where the difference lay between traditional and nontraditional students based on quality of relationships with other students, faculty, and administrative personnel. Based on the means, traditional students had higher levels of quality of relationships with other students $(M=5.64)$ compared to nontraditional students $(M=5.54)$. Nontraditional students had higher quality of relationships with faculty $(M=5.57)$ compared to traditional students $(M=5.41)$. Nontraditional students also reported higher quality of relationships with administrative personnel, with a reported mean of 4.99. Traditional college students reported a mean of 4.71. When looking at the total mean for both groups, quality of relationships with other students had the highest reported mean at 5.62.

The researcher also conducted three nonparametric Mann-Whitney tests to test the research hypothesis to see if there was any difference in the results between the parametric and nonparametric test. In the first Mann-Whitney test, the independent variable was student type (traditional or nontraditional), and the dependent variable was the quality of relationships with other students. In the Test Statistics, significance was reported at .001 for the quality of relationships with other students. Since there was a significant difference, the Rank table was utilized to analyze the mean ranks. Traditional students reported a mean rank of 9,195.77, and nontraditional students reported a mean rank at 8,882.29. In the second Mann-Whitney test, the independent variable was student type (traditional or nontraditional), and the dependent variable was the quality of relationships with faculty. In the Test Statistics, significance was reported at .000 for the quality of relationships with faculty. Since there was a significant difference, the Rank table was utilized to analyze the mean ranks. Traditional students reported a mean rank of 8,919.43, and nontraditional students reported a mean rank at 9,838.70. In the third Mann-Whitney test, the independent variable was student type (traditional or nontraditional), and the dependent variable was the quality of relationships with administrative personnel. In the Test Statistics, significance was .000 for the quality of relationships with administrative personnel. Since there was a significant difference, the Rank table was utilized to analyze the mean ranks. Traditional students reported a mean rank of 8,889.38, and nontraditional students reported a mean rank at 9,942.73. Table 5 reports the mean ranks and significance levels of traditional and nontraditional students for quality of relationships with other students, faculty, and administrative personnel.

\section{Discussions}

\subsection{Research Hypothesis 1}

There is a significant difference in academic performance of traditional and nontraditional college students based on the level of student engagement. To be able to test this research hypothesis, two-way chi-square was used to determine if there was a significant difference between student type (traditional or nontraditional) and academic performance, and Two-group MANOVA was used to determine if there was significant difference between the student type (traditional or nontraditional) and the level of student engagement based on the five benchmarks of effective education practice. Based on the data from the two-way 
chi-square, there was a significant difference in the association and relationship between student type (traditional and nontraditional) and academic performance. The observed count percentages indicated nontraditional college students reported more grades of $\mathrm{A}$ and $\mathrm{A}$ - than traditional college students. More traditional students reported grades of $\mathrm{B}+, \mathrm{B}, \mathrm{B}-, \mathrm{C}+, \mathrm{C}$, and C-lower; however, it was only by a small margin. Nevertheless, since A and A- are the ideal grades of academic performance, nontraditional college students had a higher academic performance than traditional college students. The results from this study were in line with the outcomes of previous studies. Fairchild (2003), Kasworm (2003), Kasworm and Pike (1994), and Svanum and Bigatti (2009) reported nontraditional students has higher grades and grade point averages than traditional students. However, Justice and Dornan (2001) revealed there was no significant difference in grades between traditional and nontraditional students. Though previous studies showed some differences, the current study added to the body of knowledge regarding a difference between grades of traditional and nontraditional college students. It supported the evidence of nontraditional students having higher grades than traditional students.

Secondly, the two-group MANOVA was utilized to determine if there was a significant difference between student type (traditional and nontraditional) and level of student engagement based on the five benchmarks of effective educational practice. Based on the data, it was reported there was a significant difference between student type and level of student engagement based on the collection of the dependent variables. Level of academic challenge, student-faculty interaction, supportive campus environment, and enriching educational experiences all contributed to the statistically significant difference. After analyzing the means, nontraditional college students had higher levels of academic challenge $(M=57.446)$ compared to traditional students $(M=56.474)$. Traditional college students, on the other hand, reported higher levels of student engagement in the benchmarks of student-faculty interaction ( $M=40.014)$, supportive campus environment $(M=62.135)$, and enriching educational experiences $(M=36.462)$ compared to nontraditional students. Therefore, traditional college students had statistically higher levels of student engagement based on the five benchmarks compared to nontraditional college students. The total means was also used to determine that supportive campus environment was the highest benchmark in the student engagement process with a reported total mean of 61.583. These results were similar to that of previous research. Numerous studies have validated the results of traditional college students having higher levels of student engagement compared to nontraditional students (Bradley \& Graham, 2000; Choy, 2002; DiMaria, 2006; Gibson \& Slate, 2010; Gilardi \& Guglielmetti, 2011; Lerer \& Talley, 2010; Morgan, 2001; Spitzer, 2000; Strage, 2008). Furthermore, there are also several aspects that are different and contribute to scholarly research. Fuller et al. (2011) noted level of academic challenge and active and collaborative learning had the largest significant difference for traditional students. However, based on the results of the current study, student-faculty interaction, supportive campus environment, and enriching educational experiences was the highest benchmarks of the student engagement process for traditional students. Thus, future research could be conducted to determine the highest benchmarks of the level of student engagement for traditional college students. Finally, there was a gap in literature in examining the five benchmarks of 
the student engagement process of nontraditional students. Therefore, this study was able to add to this gap regarding the level of student engagement based on the five benchmarks for nontraditional students.

\subsection{Research Hypothesis 2}

A traditional college student's level of student engagement has a significant impact on the quality of relationships that they have with other students, faculty, and administrative personnel. Three separate Kendall's tau-b statistical tests were utilized to test this hypothesis. Based on the data, the level of student engagement for traditional students had a significant impact upon the quality of relationships other students, faculty, and administrative personnel. The level of student engagement had the most significant impact on quality of relationships with faculty (.398). It had the second largest significant impact on quality of relationships with other students (.327), and the third largest impact on quality of relationships with administrative personnel (.284) for traditional college students. Graunke and Woosley (2005) and Rugutt and Chemosit (2009) reported the level of student engagement had a significant impact on the quality of relationships with other students, quality of relationships with faculty, and quality of relationships with administrative personnel. However, Ullah and Wilson (2007) noted the level of student engagement had the largest impact on quality of relationships with peers and the second largest impact on quality of relationships with faculty. The current study differed as the level of student engagement had the largest impact on the quality of relationships with faculty. The results of the current study continued to add to the body of knowledge regarding the student engagement process of traditional students and its impact on the quality of relationships.

\subsection{Research Hypothesis 3}

A nontraditional college student's level of student engagement has a significant impact on the quality of relationships that they have with other students, faculty, and administrative personnel. Three separate Kendall's tau-b statistical tests were utilized to test this hypothesis. Based on the data, the level of student engagement of nontraditional college students had a significant impact on the quality of relationships with other students, faculty, and administrative personnel. The level of student engagement has the most significant impact on quality of relationships with faculty (.395). It has the second largest impact upon quality of relationships with other students (.360), and the third largest impact on quality of relationships with administrative personnel (.298). To compare the results with those in Research Hypothesis 2, level of student engagement of traditional college students had a more significant impact on quality of relationships with faculty compared to nontraditional students. The level of student engagement of nontraditional students, on the other hand, had a more significant impact on quality of relationships with other students and administrative personnel compared to traditional college students. However, the level of student engagement had a more significant impact on quality of relationships with other students and with faculty compared to the quality of relationships with administrative personnel for both student types, traditional and nontraditional students. Rosenthal et al. (2000) and Wyatt (2011) reported similar findings regarding the impact of the level of student engagement had upon the quality 
of relationships with other students and faculty. Nevertheless, there was a gap in the literature regarding the impact the level of student engagement had upon the quality of relationships with administrative personnel. The current study added to the gap within the literature. Delaney (2008) revealed the level of student engagement had the largest impact on the quality of relationships with faculty for both traditional and nontraditional students as well, which is similar to the findings of the current study. The findings of the current study continued to add to the body of knowledge regarding the impact student engagement can has upon the educational and academic activities of traditional and nontraditional students.

\subsection{Research Hypothesis 4}

There is a significant difference in the quality of relationships that traditional college students have with other students, faculty, and administrative personnel compared to that of nontraditional college students. A two-group MANOVA was utilized to test this research hypothesis. As stated previously, the two-group MANOVA was selected based on the continuity and continuum of data because the Likert scale used to measure quality of relationships was 1 through 7, instead of smaller ranges. Based on the data of the two-group MANOVA, there was a significant difference in the quality of relationships that traditional college students have with other students, faculty, and administrative personnel compared to nontraditional college students. It was reported there was a significant difference between student type (traditional and nontraditional) and quality of relationships with other students, faculty, and administrative personnel based on the collection of the dependent variables. The quality of relationships with other students, quality of relationships with faculty, and quality of relationships with administrative personnel all differed between traditional and nontraditional students. By looking at the means, traditional college students had higher quality of relationships with other students $(M=5.64)$ compared to nontraditional students $(M=5.54)$. Nontraditional college students, on the other hand, had higher quality of relationships with faculty $(M=5.57)$ compared to traditional students $(M=5.41)$. Additionally, nontraditional college students had higher quality of relationships with administrative personnel $(M=4.99)$ compared to traditional students $(M=4.71)$.

Furthermore, to also test this research hypothesis, nonparametric Mann-Whitney tests were used to determine if any different results would be generated by using a parametric and nonparametric statistical analysis. Three separate Mann-Whitney analyses were conducted to test the quality of relationships with other students, faculty, and administrative personnel between traditional and nontraditional college students. Based on the data, there was a significant difference in the quality of relationships that traditional college students have with other students, faculty, and administrative personnel compared to nontraditional college students. Traditional college students had higher quality of relationships with other students $(9,195.77)$ compared to nontraditional students $(8,882.29)$. However, nontraditional college students had higher quality of relationships with faculty $(9,838.70)$ compared to traditional college students $(8,919.43)$. Additionally, nontraditional college students had higher quality of relationships with administrative personnel $(9,942.73)$ compared to traditional college students $(8,889.38)$. Therefore, the same results and outcomes were reported from both the two-group MANOVA and three Mann-Whitney tests. Lundberg (2003a) found nontraditional 
students had higher quality of relationships with faculty based on the level of student engagement compared to traditional students. Results also revealed traditional students had higher quality of relationships with other students based on the level of student engagement compared to nontraditional students. These finds were comparable to the findings of the current study. Between all of the relationships, the quality of relationships with administrative personnel for both traditional and nontraditional students was the lowest. Additional research on this could be warranted.

\subsection{Implications}

The results of this study provide numerous implications for the educational community. Because traditional college students and nontraditional students were analyzed, a better insight and understanding of student engagement model for each student type is provided. Institutions and administrators are able to create, modify, or adjust programs and services for traditional and nontraditional students. By providing specific programs and services built on research, institutions are able to be more effective in achieving the goals and objectives set forth in targeting traditional and nontraditional college students, which can help enhance recruitment, retention, academic performance, and graduation rates (Karemera et al., 2003). As discussed, the level of student engagement was determined by the scores of the five benchmarks of effective educational practice. Because of this, this study is able to be compared to similar studies and institutional reports that use the five benchmarks of effective educational practice for measurement purposes. This will allow higher education administrators to be able to survey and measure smaller samples and compare the results to those of a national sample. Moreover, since this study contained a national sample, it was not limited to one specific institution or region of the country. Therefore, the results of this study may be more generalized.

Additionally, because the quality of relationships with faculty was the highest quality of relationship for both traditional and nontraditional students, it is important for institutions to continue to create opportunities for engagement with faculty inside and outside of the classroom for the quality of relationships to continue to grow (Graham \& Gisi, 2000). The results of this study indicate the engagement levels of nontraditional students are lower compared to traditional college students. Therefore, administrators should design specific initiatives tailored particularly to the needs, schedules, and lives of nontraditional college students in order to increase the levels of student engagement. Finally, the results of this study can help collaboration between academic affairs and student affairs offices achieve the same results as student engagement and academic performance concerns both parties.

\subsection{Limitations}

The participants within the study were students who participated in the NSSE survey from all participating institutions from across the United States. This can provide insight into the two student groups: traditional and nontraditional. However, the results from this study may not be specific or applicable at every institution within the country. The researcher had to use the self-reported grades from The Report as the academic performance of the students. There may be discrepancy or skewedness because it is dependent upon the honesty of the students 
involved.

This study also did not take into account the institution types of the participants. There are many types of different institutions: Carnegie, 4-year, 2-year, private, and public. The type of institution could have an effect on the results of this study. The demographics and background information of students were not considered in this study either. Race, gender, economic status, parent education, and social class could have an effect upon a student's engagement and academic performance. However, this was not taken into consideration for this study.

The sample for this study was also a limitation. The sample was representative of the population of the data set from 2010 National Survey of Student Engagement; however, the sample was not representative of the United States college student population and landscape. Finally, age was the main factor used in this study to determine whether a student was classified as traditional or nontraditional. Though research has shown age is a common variable and strong predictor, this study did not include other variables such as living situation, work status, or enrollment status.

\section{References}

Astin, A. W. (1977). Four critical years: Effects of college on beliefs, attitudes, and knowledge. San Francisco: Jossey-Bass. http://dx.doi.org/10.2307/1980663

Astin, A. W. (1984). Student involvement: A developmental theory for higher education. Journal of College Student Personnel, 25(4), 297-308.

Astin, A. W. (1999). Involvement in learning revisited: Lessons we have learned. Journal of College Student Development, 40(5), 587.

Axelson, R. D., \& Flick, A. (2011). Defining student engagement. Change, 43(1), 38-43. http://dx.doi.org/10.1080/00091383.2011.533096

Bauman, S. S. M., Wang, N., DeLeon, C. W., Kafentzis, J., Zavala-Lopez, M., \& Lindsey, M. S. (2004). Nontraditional students' service needs and social support resources: A pilot $\begin{array}{lllll}\text { study. Journal of College } & \text { Counseling, }\end{array}$ http://dx.doi.org/10.1002/j.2161-1882.2004.tb00254.x

Bean, J. P., \& Metzner, B. S. (1985). A conceptual model of nontraditional undergraduate student attrition. Review of Educational Research, 55, 485-540. http://dx.doi.org/10.3102/00346543055004485

Bradley, J. S., \& Graham, S. W. (2000). The effect of educational ethos and campus involvement on self-reported college outcomes for traditional and nontraditional undergraduates. Journal of College Student Development, 41(5), 488-502.

Carini, R., Kuh, G., \& Klein, S. (2006). Student engagement and student learning: Testing the linkages. Research in Higher Education, 47(1), 1-32. 
http://dx.doi.org/10.1007/s11162-005-8150-9

Chao, R., \& Good, G. E. (2004). Nontraditional students' perspectives on college education: A qualitative study. Journal of College Counseling, 7(1), 5-12. http://dx.doi.org/10.1002/j.2161-1882.2004.tb00253.x

Choy, S. P. (2002). Findings from the condition of education 2002: Nontraditional undergraduates (NCES 2002-012). Washington, DC: National Center for Educational Statistics.

Delaney, A. M. (2008). Why faculty-student interaction matters in the first year experience. Tertiary Education $\quad \& \quad$ Management, 227-241. http://dx.doi.org/10.1080/13583880802228224

DiMaria, F. (2006). Keeping our engaged, at-risk kids in college. Education Digest, 72(2), 52-57.

Fairchild, E. E. (2003). Multiple roles of adult learners. New Directions for Student Services, 2003(102), 11-16. http://dx.doi.org/10.1002/ss.84

Fuller M.B., Wilson M.A., \& Tobin R.M. (2011). The national survey of student engagement as a predictor of undergraduate GPA: A cross-sectional and longitudinal examination. Assessment and Evaluation in Higher Education, 36(6), 735-748. http://dx.doi.org/10.1080/02602938.2010.488791

Gibson, A. M., \& Slate, J. R. (2010). Student engagement at two-year institutions: Age and generational status differences. Community College Journal of Research and Practice, 34(5), 371-385. http://dx.doi.org/10.1080/10668920802466384

Gilardi, S., \& Guglielmetti, C. (2011). University life of non-traditional students: Engagement styles and impact on attrition. Journal of Higher Education, 82(1), 33-53. http://dx.doi.org/10.1353/jhe.2011.0005

Graham, S. W., \& Gisi, S. L. (2000). Adult undergraduate students: What role does college involvement play? NASPA Journal, 38(1), 99-121. http://dx.doi.org/10.2202/1949-6605.1122

Graunke, S. S., \& Woosley, S. A. (2005). An exploration of the factors that affect the academic success of college sophomores. College Student Journal, 39(2), 367-376.

Hernandez, K., Hogan, S. L., Hathaway, C., \& Lovell, C. D. (1999). Analysis of the literature on the impact of student involvement on student development and learning: More questions than answers? NASPA Journal, 36(3), 184-197. http://dx.doi.org/10.2202/1949-6605.1082

Johnson, M. L., \& Nussbaum, E. M. (2012). Achievement goals and coping strategies: Identifying the traditional/nontraditional students who use them. Journal of College Student Development, 53(1), 41-54. http://dx.doi.org/10.1353/csd.2012.0002

Justice, E. M., \& Dornan, T. M. (2001). Metacognitive differences between traditional-age 
and nontraditional-age college students. Adult Education Quarterly, 51(3), 236-249. http://dx.doi.org/10.1177/074171360105100305

Karemera, D., Reuben, L. J., \& Sillah, M. R. (2003). The effects of academic environment and background characteristics on student satisfaction and performance: The case of South Carolina State University's School of Business. College Student Journal, 37(2), 298.

Kasworm, C. E. (2003). Setting the stage: Adults in higher education. New Directions for Student Services, 2003(102), 3-10. http://dx.doi.org/10.1002/ss.83

Kasworm, C. E., \& Pike, G.R. (1994). Adult undergraduate students: Evaluating the appropriateness of a traditional model of academic performance. Research in Higher Education, 35(6), 689. http://dx.doi.org/10.1007/bf02497082

Keith, P. M. (2007). Barriers and nontraditional students' use of academic and social services. College Student Journal, 41(4), 1123-1127.

Kim, K. A., Sax, L. J., Lee, J. J., \& Hagedorn, L. S. (2010). Redefining nontraditional students: Exploring the self-perceptions of community college students. Community College Journal of Research and Practice, 34(5), 402-422. http://dx.doi.org/10.1080/10668920701382633

Kinsella, S. (1998). A cross-discipline study of traditional and nontraditional college students. College Student Journal, 32(4), 532-538.

Koljatic, M., \& Kuh, G. D. (2001). A longitudinal assessment of college student engagement in good practices in undergraduate education. Journal of Higher Education, 42(3), 351-371. http://dx.doi.org/10.1023/a:1017993113390

Kuh, G. D. (2001). Assessing what really matters to student learning. Change: The Magazine of Higher Learning, 33(3), 10-17. http://dx.doi.org/10.1080/00091380109601795

Kuh, G. D. (2003). What we're learning about student engagement from NSSE: Benchmarks for effective educational practices. Change, 35(2), 24-32. http://dx.doi.org/10.1080/00091380309604090

Kuh, G. D. (2004). The National Survey of Student Engagement: Conceptual framework and overview of psychometric properties. New Directions for Institutional Research, 2004. Retrieved from http://nsse.indiana.edu/2004_annual_report/pdf/2004_Conceptual_Framework.pdf

Kuh, G. D. (2005). Putting student engagement results to use: Lessons from the field. Assessment Update, 17(1), 12-13.

Kuh, G. D. (2009). The National Survey of Student Engagement: Conceptual and empirical foundations. New Directions for Institutional Research, 2009(141), 5-20. http://dx.doi.org/10.1002/ir.283

Kuh, G. D., Kinzie, J., Buckley, J. A., Bridges, B. K., \& Hayek, J. C. (2007). Student 
behaviors, activities, and experiences associated with student success. In E. Ward \& L. E. Wolf-Wendel (Eds.), Piecing together the student success puzzle: Research, propositions, and recommendations: ASHE higher education report (Vol. 32, pp. 43-67). San Francisco, CA: Jossey-Bass.

Lerer, N., \& Talley, K. (2010). National survey of student engagement's (NSSE) benchmarks - one size fits all? On the Horizon, 18(4), 355-363. http://dx.doi.org/10.1108/10748121011082653

Lundberg, C. A. (2003a). The influence of time-limitations, faculty, and peer relationships on adult student learning: A causal model. Journal of Higher Education, 74(6), 665-688. http://dx.doi.org/10.1353/jhe.2003.0045

Macari, D. P., Maples, M. F., \& D'Andrea, L. (2005). A comparative study of psychosocial development in nontraditional and traditional college students. Journal of College Student Retention: Research, Theory \& Practice, 7(3), 283-302. http://dx.doi.org/10.2190/bv5h-3630-18cu-6c3b

Merwin, J. C. (1984). Involvement in learning: Realizing the potential of American higher education. Washington, DC: U. S. Department of Education.

Morgan, W. (2001). A journey through adult student involvement on campus. Journal of Student Affairs, 10(1), 1-15.

Pace, C. R. (1984). Measuring the quality of college student experiences: An account of the development and use of the college student experiences questionnaire. Los Angeles, CA: University of California, Higher Education Research Institute, Graduate School of Education.

Rosenthal, G. T., Folse, E. J., Alleman, N. W., Boudreaux, D., Soper, B., \& Von Bergen, C. V. (2000). The one-to-one survey: Traditional versus non-traditional student satisfaction with professors during one-to-one contacts. College Student Journal, 34(2), 315-320.

Rugutt, J., \& Chemosit, C. C. (2009). What motivates students to learn? Contribution of student-to-student relations, student-faculty interaction and critical thinking skills. Educational Research Quarterly, 32(3), 16-28.

Spitzer, T. M. (2000). Predictors of college success: A comparison of traditional and nontraditional age students. NASPA Journal, 38(1), 82-98. http://dx.doi.org/10.2202/1949-6605.1130

Strage, A. (2008). Traditional and non-traditional college students' descriptions of the "ideal” professor and the "ideal" course and perceived strengths and limitations. College Student Journal, 42(1), 225-231.

Svanum, S., \& Bigatti, S. M. (2009). Academic course engagement during one semester forecasts college success: Engaged students are more likely to earn a degree, do it faster, and do it better. Journal of College Student Development, 50(1), 120-132. http://dx.doi.org/10.1353/csd.0.0055 
Tyler, R. (1969). Educational evaluation: New roles, new methods: The sixty-eighth yearbook of the National Society for the Study of Education, Part II. Chicago, IL: University of Chicago Press.

Ullah, H., \& Wilson, M. A. (2007). Students' academic success and its association to student involvement with learning and relationships with faculty and peers. College Student Journal, 41(4), 1192-1202.

Wyatt, L. G. (2011). Nontraditional student engagement: Increasing adult student success and retention. Journal of Continuing Higher Education, 59(1), 10-20. http://dx.doi.org/10.1080/07377363.2011.544977

\section{Copyright Disclaimer}

Copyright reserved by the author(s).

This article is an open-access article distributed under the terms and conditions of the Creative Commons Attribution license (http://creativecommons.org/licenses/by/3.0/). 